\title{
Assessing Counselors' Self-Efficacy in Suicide Assessment and Intervention
}

By: Kerrie Anna Douglas, Carrie A. Wachter Morris

Douglas, K. A., \& Wachter Morris, C. A. (2015). Assessing counselors' self-efficacy in suicide assessment and intervention. Counseling Outcome Research and Evaluation, 6(1), 58-69. http://dx/doi.org/10.1177/21501378145671.

Made available courtesy of Sage Publications: http://dx.doi.org/10.1177/2150137814567471

***(C) The Authors. Reprinted with permission. No further reproduction is authorized without written permission from the authors and Sage Publications. This version of the document is not the version of record. Figures and/or pictures may be missing from this format of the document. ***

\begin{abstract}
:
Council for Accreditation of Counseling and Related Educational Programs Standards state that counseling students must be adequately trained in suicide assessment and intervention. To evaluate how well students or practicing counselors are prepared, there is a need to measure selfefficacy specific to the tasks required in suicide assessment and intervention. The purpose of this study was to develop and assess the validity evidence for the Counselor Suicide Assessment Efficacy Survey (CSAES), a measure of self-efficacy related to suicide assessment and intervention. CSAES was studied for use in measuring the outcomes of suicide assessment curricular and professional development. Detailed results of reliability and validity studies are reported.
\end{abstract}

Keywords: counselor self-efficacy | suicide assessment | outcome measure

\section{Article:}

Suicide is a serious U.S. public health issue that is occurring at alarming rates, and professional counselors are commonly confronted with clients who express suicidal thoughts or behaviors. According to the Center for Disease Control and Prevention (CDC; 2012), in 2010, every 13.7 minutes an individual dies life by committing suicide. In addition, suicide was the third leading cause of death for persons aged 10 to 24, equating to $20.6 \%$ of all deaths in this age-group. In a typical high school classroom, three students have attempted suicide in the previous 12 months (American Association of Suicidology, 2013). With statistics as startling as the CDC and American Association for Suicidology provide, it is unrealistic for counselors to merely hope all clients value their own life and have ruled out the possibility of suicide. Counselors must be prepared to assess and intervene on behalf of a potential suicidal client with little to no prior notice. 
Yet suicide assessment is an area that counselors may feel particularly low in efficacy, as one study of school counselors found only $38 \%$ believed they were capable of recognizing a student at risk for suicide (King, Price, Telljohann, \& Wahl, 1999). King, Price, Telljohann, and Wahl's (1999) research has been partially corroborated by a more recent study in which $26.95 \%$ of the counselors in their first 2 years of practice reported having either "no" or "minimal" training in suicide assessment (Wachter Morris \& Barrio Minton, 2012). These statistics are particularly alarming, considering the role that counselors' beliefs in their capabilities play in the decisions they make when counseling someone (Larson \& Daniels, 1998).

Clearly, there is a need for counselors to be efficacious and competent in suicide assessment and intervention. Recognizing this need, the 2009 Council for Accreditation of Counseling and Related Educational Programs (CACREP) Standards stated that counselors in training should be able to appropriately manage suicide risk and assess for suicidality (e.g., Addiction Counseling D4, H3; Clinical Mental Health Counseling D6, H3; Marriage Couples and Family Counseling D4; School Counseling D4; and Student Affairs and College Counseling D.4).

Over 25 years ago, Bandura (1986, p. 21) asserted, "Among the types of thoughts that affect action, none is more central or pervasive than people's judgments of their capabilities to deal effectively with different realities.' His strong assertion has withheld the test of time and scrutiny of many empirical studies that extend well beyond Bandura's early writings. In relation to counselor training, Larson and Daniels (1998, p.180) provide a definition of counselor selfefficacy "as one's beliefs or judgments about her or his capabilities to effectively counsel a client in the near future."

The research on counselor self-efficacy has become an important area of study, with research on both general counselor self-efficacy and self-efficacy specific to certain counseling tasks (Lent, Hill, \& Hoffman, 2003). Larson and Daniels (1998) conducted a review of the counselor selfefficacy literature and found that it influences the choices a counselor makes in terms of engaging in counseling, actions taken during counseling sessions, and responses given to clients. They also note that counselor self-efficacy has been found to be a predictor of how counselors approach difficult situations, expend continued effort with clients, and show persistence in challenging situations. Although self-efficacy does not guarantee a strong skill set (nor does the lack of self-efficacy mean that a counselor lacks relevant skills), Larson and Daniels assert that counselor self-efficacy is the bridge between knowing how to counsel a client and actually counseling through effective actions. In other words, a counselor may possess adequate skill levels to appropriately assess a clients' risk of suicide, but because of low self-efficacy the counselor is not actually performing the assessment or performing it poorly. Based on previous work in counselor self-efficacy, it is reasonable to expect that the degree to which a counselor has self-efficacy related specifically to suicide assessment and intervention will influence their willingness to engage clients who are at suicide risk. This is contrasted with possessing knowledge about how to assess and intervene in such situations, but avoiding the topic because of a doubt in capability. It is hypothesized that the higher the degree of self-efficacy related to 
suicide assessment and intervention, the better the assessment and intervention given to a possible suicidal client.

A self-efficacy instrument specific to suicide assessment and intervention is needed to adequately address the needs of counselors in training and evaluate efforts to prepare them for suicide assessment and intervention. Furthermore, there is a need to research the relationship between the level of counselor self-efficacy related to suicide assessment and intervention and how counselors respond when faced with a potentially suicidal client. In response to these needs and with the hope of opening future research possibilities, the purpose of this study is the development and validation of the Counselor Suicide Assessment Efficacy Survey (CSAES), an instrument designed to measure counselor's self-efficacy in suicide assessment and intervention.

\section{Methods and Procedures}

The development of the CSAES was based on the guidelines for scale construction as recommended by Netemeyer, Bearden, and Sharma (2003) and following the American Counseling Association (ACA) Code of Ethics (2014), and occurred in two phases. The first phase, construction of CSAES, entailed (a) ensuring that self-efficacy as a construct was appropriately defined and measured as discussed by Bandura (2006), (b) establishing the scope of domain for items, and (c) generating and evaluating items based on field testing and pilot study. The second phase involved the psychometric examination of the CSAES with four main objectives, namely, (a) assess scale reliability, (b) establish initial factor structure, (c) crossvalidate factor structure, and (d) assess the sensitivity of the scale through comparison of counseling graduate student and faculty scores.

Phase 1: Construction of the CSAES

In keeping with ACA (2014) guidelines for assessment construction, we first reviewed Bandura's (1986, 2006) work on self-efficacy and his recommendations on how to create a selfefficacy scale. Self-efficacy is the belief in personal capabilities related to specific domains (Bandura, 1986). Although Bandura (1986) discusses the four sources of self-efficacy (verbal persuasion, vicarious experience, physiological arousal, and mastery experience), these are not direct measures of self-efficacy. Rather, he discusses the sources of self-efficacy as influences on a person's belief in their capability. In addition, while there is interplay between outcome expectancy and self-efficacy, Bandura (2006) clarifies that they should be distinguished from one another as constructs. He also provides several examples of how self-efficacy items should be worded and discusses the need to adequately cover varying difficulty levels in order to avoid ceiling effects.

A survey was conducted to identify previous measures of self-efficacy related to suicide assessment and intervention that have been psychometrically studied and published in peerreview journals. King and Smith (2000) developed a perceived knowledge of suicide intervention and efficacy expectation scales for the purpose of evaluating a suicide assessment 
and intervention training program. They established internal consistency for these, but did not examine factor structure. In addition, both scales contain few items that tap a more broad level of self-efficacy related to suicide assessment and intervention.

The next step involved defining the scope of CSAES. We decided that items would be developed specific to the constructs of suicide assessment and suicide intervention; conceptually being a two-factor model. Our goal was to create a measure of self-efficacy relative to specific aspects of suicide assessment and intervention, as opposed to self-efficacy about suicide assessment in general. We also took care to ensure that items reflected the various levels of difficulty that naturally occur when counseling someone at risk for suicide. In order to develop items that reflected the various counseling tasks that are involved in suicide assessment, the assessment items are based on suicide risk factors and warning signs as described by the National Institute for Mental Health (www.nimh.nih.gov) and American Association for Suicidology (www.suicidology.org). Items were written to reflect both the general suicide assessment questions (e.g., asking about suicidal thoughts) and assessment questions that invoke varying degrees of personal information that may be related to suicide risk (e.g., asking about acceptance of sexuality) and family history of suicide. Most of the items that relate to suicide intervention were developed based on the levels of risk that a counselor assesses. Also added were items based on the second author's personal experiences in training future counselors and providing professional development for practicing counselors. For example, in the classroom, students have mentioned concern about what to do when a counselor does not believe a client is being forthcoming in suicidal ideation. This process resulted in generating 31 potential items for CSAES. Following the guidelines from Bandura (2006), respondents were asked to rate each item on a scale of 0 to 100; 0 means cannot do at all and 100 means highly certain can do.

The next step involved an initial field test of 31 items, following the cognitive interview guidelines from Blair, Czaja, and Blair (2014). In cognitive interviews, participants are asked to think out loud as they answer each question in the survey. The researcher observes and notes how each respondent reads, thinks about, and answers each question. The main purpose of the cognitive interviews is to gather evidence that items are read and interpreted in a manner as intended by the researchers. In addition, problematic wording, issues of potential bias, and other technical feedback on items can be obtained. Cognitive interviews were performed with five counseling psychology PhD students, four females and one male, all in their third or fourth year of academic program. Four participants self-identified as Caucasian and one self-identified as African American. Based on the participant feedback, minor revisions were made in wording of items and 2 items were discarded as being redundant.

Next, the 29 CSAES items were piloted at two master's-level counseling programs, one at a large Midwestern university and the other a small Southern University. Students at the first site had completed 1 year of their graduate program. Students at the second site were in their first semester of their graduate program. Because of the small cohorts in the counseling programs, the sample size of responses was low $(n=16)$. However, the pilot test results did bring up areas for 
reevaluation. Individual surveys gave the appearance that respondents wrote in the same number on every item per page. In addition, responses were only given in the 10s, not utilizing the 100point scale. Following the example of Lent, Hill, and Hoffman's (2003) Counselor Activity SelfEfficacy Scale, item responses were changed to a 5-point, $1=$ strongly disagree to $5=$ strongly agree format. Also, items were no longer condensed in a matrix format, but formatted to allow more space between items by placing answer choices under each statement.

\section{Participants}

Participants were recruited through three professional listservs; Counselor Educator and Supervisor Network (CESNET), CounselorTalk (the listserv for Indiana school counselors), and New Faculty Interest Network (NFIN). Following Institutional Review Board (IRB) protocol for exempt survey research, participants read a brief introduction to the purpose of the survey and then clicked on a survey link. The e-mailed survey link resulted in 268 participants. Next, we recruited graduate students in counseling courses at 11 different universities as part of a larger study, where curriculum was also being tested. Following IRB protocol for expedited research, students were given informed consent concerning the larger project, as well as asked to complete the CSAES. This resulted in an additional 90 participants. In both recruitment procedures, participants could discontinue the survey at any time. We cleaned the data by deleting cases where $50 \%$ or more of the responses were left blank, leaving 324 total respondents. This resulted in negligible missing data, which was handled by full information maximum likelihood estimation in Mplus (Muthen \& Muthen, 2010). Sixty-one (18.83\%) participants were male, 258 $(79.63 \%)$ were female, and four $(1.23 \%)$ did not respond. Ninety-three (28.70\%) participants were master's-level counseling students, $2(0.62 \%)$ respondents were doctoral counseling students, 123 (37.96\%) held master's degrees, 95 (29.32\%) held PhDs, and $11(3.40 \%)$ indicated that they have bachelor's degrees. Of the participants who were not graduate students $(n=95)$, approximately one quarter each were university faculty $(\mathrm{n}=81)$ or mental health clinicians $(\mathrm{n}=$ $78)$. The remaining respondents were school counselors $(n=46 ; 14.20 \%)$, supervisors $(n=8$; $2.45 \%)$, or reported their job status as "other" or did not respond ( $\mathrm{n}=17 ; 5.25 \%)$. In scale development, it is common practice to first assess an instrument through exploratory factor analysis (EFA) and then to evaluate the stability of the factor structure on a different data set through confirmatory factor analysis (CFA; Worthington \& Whittaker, 2006). In order to create two data sets for this cross-validation, these data were randomly split in half for EFA and CFA.

\section{Procedures}

In the following procedures, we followed Fabrigar, Wegener, MacCallum, and Strahan's (1999) step-by-step recommendations for EFA. We first examined the characteristics of the data before proceeding to the main analysis. In order to examine the appropriateness of scaling the items, Cronbach's a was calculated for all items and found to be high, especially for a newly developed scale $(\mathrm{a}=.954)$. Data were checked for normality assumptions based on skewness, kurtosis, means, and standard deviations. The skew and kurtosis were found to be within an acceptable 
range (3 and 10, respectively; Thompson, 2004). However, because means and standard deviations did not support normality, these data were treated as nonnormal. In addition, item correlations were examined for multicollinearity (correlations over .85), and all fell within acceptable range of correlation, indicating that each item measured a different aspect. Observed initial communalities revealed that all of the items were acceptable (>.30) for use in the EFA.

For the next stage of analysis, the factor structure found in the EFA was modeled in a CFA with the other half of the data set, using weighted least squares estimation (WLSMV) in Mplus 6.0 (Muthen \& Muthen, 2010). WLSMV is the default option in Mplus for CFA when the data are considered nonnormal. In the output, Mplus 6.0 (Muthen \& Muthen, 2010) provides suggested modifications to the model based on the data and includes modification indices to aid in evaluating how well the revision would improve model fit. The data produced suggested modifications were considered based on theoretical and empirical justifications. An unstructured model was also estimated, as well as alternative models. Thompson and Daniel (1996) recommend the testing of alternative models as a way of further assessing construct validity. The models were evaluated based on goodness-of-fit statistics, specifically, comparative fit index (CFI), Tucker-Lewis fit index (TLI), and root mean square error of approximation (RMSEA). The CFI and TFI compare the estimated model to the baseline model, where values closer to 1.0 indicate a good fit (Byrne, 2012). The RMSEA evaluates how well the specified model actually fits the data. Values of 0.05 indicate a good fit, where values of 0.08 and higher indicate a misspecification in the model (Byrne, 2012).

For CSAES to have utility in assessing a range of skill levels, it is imperative that groups of higher ability have higher scores. A comparison between two groups of different experience levels provides evidence of the sensitivity of an assessment to measure differences. We examined whether the CSAES was sensitive enough to detect differences between varying levels of counseling experience by conducting independent $\mathrm{t}$-tests between graduate student scores $(\mathrm{n}=$ 98; 96 master's level and 2 doctoral level) and faculty scores $(\mathrm{n}=81)$ on each subscale.

\section{Results}

EFA

An EFA was conducted on all 29 items in SPSS (version 22) using principal axis estimation, with a Promax rotation to allow factors to be correlated or not correlated. We used Eigenvalues, scree plot, factor loadings, and interpretability to aid in determination of the number of factors (see Fabrigar, Wegener, MacCallum, \& Strahan, 1999). Based on Eigenvalues and scree plot, a five-factor model was suggested. However, upon examination, one of the factors was comprised only of items that were cross-loading significantly (>.30) on other factors. The four-factor model was then considered. All items significantly loaded on at least one factor. Items that loaded on factors that conceptually did not make sense (e.g., an intervention item falling into an assessment factor) were deleted from the scale, eliminating 4 items. The EFA was again run in SPSS to test 
the remaining 25 items. The Eigenvalues and scree plot suggested a four-factor model best represent the data. The four-factor solution that emerged reflected three aspects of assessment and one intervention: General Suicide Assessment, Assessment of Personal Characteristics, Assessment of Suicide History, and Suicide Intervention. Items that cross-loaded on two factors were noted as to be examined further in the CFA. Table 1 lists each factor and the item loadings, with means and standard deviations.

\section{CFA}

The second half of the data was tested in a CFA using maximum likelihood estimation in Mplus ( $\mathrm{n}=162$; Muthen $\&$ Muthen, 2010) as a cross-validation of the factor structure. All factors were found to be highly correlated (>.74). The following three alternative models were also tested: an unstructured model, a two-factor model (suicide assessment and suicide intervention), and a second-order factor of suicide assessment, where the three assessment factors were estimated as comprising the higher factor and the intervention factor. Thompson (2004) suggests that researchers should routinely check for a higher order factor when factors are correlated and theoretically represent a construct. The suggested modifications provided by Mplus (Muthen \& Muthen, 2010) were considered based on theoretical and statistical justifications. Items that referred to a similar situation, but differed based on whether the item was related to assessment or intervention, were allowed to correlate. In addition, Question 9 changed factors. In the EFA, Question 9 loaded in the General Suicide Assessment factor, but in the CFA changed was found to conceptually and empirically fit with the factor of Assessment of Personal Characteristics.

The four-factor model of General Suicide Assessment, Assessment of Personal Characteristics, Assessment of Suicide History, and Suicide Intervention was found to be statistically no different than the model where Suicide Assessment is a second-order factor comprised of General Suicide Assessment, Assessment of Personal Characteristics, and Assessment of Suicide History. Both models were found to have acceptable fits, based on the CFI, TLI, and RMSEA fit statistics. However, the two-factor model of Suicide Assessment and Suicide Intervention did not produce acceptable fit statistics, indicating that the individual factors of General Suicide Assessment, Assessment of Personal Characteristics, and Assessment of Suicide History were important aspects in understanding the micro-skills associated with suicide assessment self-efficacy. In addition, we concluded the unstructured model inadequately represented the data based on the goodness-of-fit indices (e.g., RMSEA of .124). Table 2 lists each model, the w2, degrees of freedom, CFI, TLI, and RMSEA statistics. The range of standardized estimates for items belonging to the four factors is from .25 to .94 , indicating that each item contributes to the construct being represented. In addition, the standardized estimates for factors comprising a second-order factor of Suicide Assessment are quite high, ranging from .86 to .99. This is further evidence that a second-order factor is being represented. According to Thompson (2004), the interpretation of the second-order factor should be based on finding broader areas of generalizeability and to improve theoretical understanding of what is being measured. In this case, the first-order factors allow a more in-depth understanding of micro-skills in suicide 
assessment, whereas the second-order factor of Suicide Assessment allows a broader understanding of varying aspects of suicide assessment. Table 3 shows the standardized estimates for each item, according to factor, as well as the standardized estimates for the factors of General Suicide Assessment, Assessment of Personal Characteristics, and Assessment of Suicide History comprising the second-order factor of Suicide Assessment.

In order to assess the internal reliability of the final model for CSAES, Cronbach's a was calculated for each of the four scales and the second-order factor; General Suicide Assessment a $=.882$ (7 items), Assessment of Personal Characteristics a $=.88$ (10 items), Assessment of Suicide History $\mathrm{a}=.81$ ( 3 items), Suicide Intervention $\mathrm{a}=.83$ (5 items), and Suicide Assessment $\mathrm{a}=.93$ (20 items). All of these reliability coefficients are high, particularly for a newly developed scale (Tinsley \& Tinsley, 1987).

Table 1. Factor Loadings for Exploratory Factor Analysis With Promax Rotation, With Means and Standard Deviations.

\begin{tabular}{|c|c|c|c|c|c|c|}
\hline Items & F1 & $\mathrm{F} 2$ & F3 & $\mathrm{F} 4$ & $\mathrm{M}$ & SD \\
\hline \multicolumn{7}{|l|}{ Factor 1: General Suicide Assessment } \\
\hline $\begin{array}{l}\text { Q8. I can effectively inquire if a student has had thoughts of } \\
\text { killing oneself }\end{array}$ & 0.66 & 0.01 & 0.32 & $\overline{-}-12$ & 4.52 & 0.70 \\
\hline Q9. I can effectively assess hopelessness & 0.34 & 0.28 & 0.12 & 0.08 & 4.10 & 0.81 \\
\hline $\begin{array}{l}\text { Q10. I can effectively assess whether a student has means to } \\
\text { carry out a suicide plan }\end{array}$ & 0.78 & -0.16 & 0.16 & - & 4.23 & 0.87 \\
\hline $\begin{array}{l}\text { Q18. I can effectively inquire whether a student has a } \\
\text { suicide plan }\end{array}$ & 0.88 & 0.02 & 0.05 & 0.18 & 4.43 & 0.79 \\
\hline $\begin{array}{l}\text { Q23. I can effectively counsel a student who has had a } \\
\text { history of making suicidal threats, but has had no attempts }\end{array}$ & 0.59 & 0.34 & $\overline{0}-\mathbf{0}$ & $\overline{0}-04$ & 3.87 & 0.91 \\
\hline $\begin{array}{l}\text { Q24. I can effectively counsel a student who has previously } \\
\text { attempted suicide }\end{array}$ & 0.65 & 0.34 & $-\overline{0}$ & $-\overline{0}(12$ & 3.80 & 1.02 \\
\hline $\begin{array}{l}\text { Q28. I am able to assess a student's level of risk for a } \\
\text { suicide attempt }\end{array}$ & 0.96 & - & 0.01 & $\overline{-}-11$ & 3.97 & 0.87 \\
\hline Q29. I can help prevent a suicide attempt & 0.67 & $-\overline{0}$ & 0.00 & 0.03 & 3.68 & 0.97 \\
\hline \multicolumn{7}{|l|}{ Factor 2: Assessment of Personal Characteristics } \\
\hline $\begin{array}{l}\text { Q4. I can effectively ask a student about his or her drug or } \\
\text { alcohol abuse }\end{array}$ & $-\overline{0}(166$ & 0.61 & 0.22 & 0.13 & 4.32 & 0.75 \\
\hline $\begin{array}{l}\text { Q5. I can effectively ask a student about his or her history } \\
\text { of sexual abuse. }\end{array}$ & $-\overline{0}(184$ & 0.79 & 0.37 & $-\overline{0}$ & 3.94 & 0.95 \\
\hline $\begin{array}{l}\text { Q6. I can effectively ask a student about his or her history } \\
\text { of mental illness }\end{array}$ & 0.106 & 0.53 & 0.28 & $\overline{-}-03$ & 4.22 & 0.87 \\
\hline $\begin{array}{l}\text { Q7. I can effectively ask a student questions to assess } \\
\text { whether he or she has low self-esteem }\end{array}$ & $\overline{-}-103$ & 0.43 & $\overline{0}-\overline{0}$ & 0.39 & 4.28 & 0.81 \\
\hline $\begin{array}{l}\text { Q11. I can effectively inquire whether a student has } \\
\text { withdrawn from relationships }\end{array}$ & 0.361 & 0.39 & $\overline{-}-05$ & 0.02 & 4.18 & 0.78 \\
\hline $\begin{array}{l}\text { Q12. I can effectively assess a student's acceptance of } \\
\text { sexuality }\end{array}$ & 0.079 & 0.69 & 0.07 & $-\overline{0}(14$ & 3.70 & 0.99 \\
\hline Q13. I can effectively talk with a student about his or her & - & 0.69 & - & 0.14 & 3.53 & 10.38 \\
\hline
\end{tabular}




\begin{tabular}{|c|c|c|c|c|c|c|}
\hline hygiene & 0.021 & & 0.27 & & & \\
\hline $\begin{array}{l}\text { Q14. I can effectively discuss with a student his or her } \\
\text { writings about death }\end{array}$ & 0.282 & 0.41 & 0.10 & 0.16 & 4.17 & 0.82 \\
\hline $\begin{array}{l}\text { Q25. I can appropriately inquire whether a student has been } \\
\text { a victim of abuse }\end{array}$ & 0.124 & 0.74 & 0.08 & $-\overline{0}(13$ & 4.08 & 0.89 \\
\hline \multicolumn{7}{|l|}{ Factor 3: Assessment of Suicide History } \\
\hline $\begin{array}{l}\text { Q1. I can effectively ask a student about his or her previous } \\
\text { suicide attempts }\end{array}$ & 0.272 & -0.02 & 0.75 & 0.01 & 4.50 & 0.64 \\
\hline $\begin{array}{l}\text { Q2. I can effectively ask a student about his or her personal } \\
\text { history of self-harming behavior }\end{array}$ & $\overline{-}-002$ & 0.25 & 0.57 & 0.14 & 4.49 & 0.63 \\
\hline $\begin{array}{l}\text { Q3. I can effectively ask a student about his or her family } \\
\text { history of suicide }\end{array}$ & $-\overline{0}+046$ & 0.360 & 0.50 & 0.02 & 4.40 & 0.81 \\
\hline \multicolumn{7}{|l|}{ Factor 4: Suicide Intervention } \\
\hline $\begin{array}{l}\text { Q15. I know the point at which I need to break } \\
\text { confidentiality }\end{array}$ & $-\overline{0}-236$ & 0.02 & 0.07 & 0.94 & 4.37 & 0.68 \\
\hline $\begin{array}{l}\text { Q16. I am able to appropriately intervene if a student } \\
\text { reports suicidal thoughts, but I do not believe him or her. }\end{array}$ & 0.109 & 0.19 & - & 0.60 & 3.85 & 1.02 \\
\hline $\begin{array}{l}\text { Q17. I am able to intervene appropriately if a student denies } \\
\text { suicidal thoughts, but I do not believe him or her }\end{array}$ & 0.141 & 0.33 & 0.19 & 0.52 & 3.80 & 1.02 \\
\hline $\begin{array}{l}\text { Q21. I can appropriately take action if I determine a student } \\
\text { is moderately at risk for suicide }\end{array}$ & 0.275 & -0.20 & 0.20 & 0.63 & 4.11 & 0.85 \\
\hline $\begin{array}{l}\text { Q22. I can appropriately intervene if a student is at } \\
\text { imminent risk for suicide }\end{array}$ & 0.195 & -0.23 & 0.27 & 0.58 & 4.43 & 0.84 \\
\hline
\end{tabular}

Table 2. Fit Statistics for Tested Confirmatory Factory Analysis Models.

\begin{tabular}{|l|l|l|l|l|l|}
\hline Model & $\chi^{2}$ & df & CFI & TLI & RMSEA \\
\hline Unstructured & $1,352.55$ & 377 & .805 & .79 & .124 \\
\hline 2 Factors & 917.18 & 274 & .841 & .826 & .119 \\
\hline 4 Factors & 494.89 & 257 & .941 & .931 & .074 \\
\hline 4 Factors and Second Order & 499.99 & 259 & .940 & .931 & .075 \\
\hline
\end{tabular}

Note. $\mathrm{N}=162$. $\mathrm{CFI}=$ comparative fit index; TLI = Tucker-Lewis fit index; RMSEA = root mean square error of approximation. Two-factor model includes Suicide Assessment and Suicide Intervention. Four-factor model includes General Suicide Assessment, Assessment of Personal Characteristics, Assessment of Suicide History, and Suicide Intervention. The second order refers to a higher order factor of Suicide Assessment.

Table 3. Standardized Pattern Coefficients for Final Model.

\begin{tabular}{|l|l|l|l|l|l|l|l|l|l|}
\hline Item & $\begin{array}{l}\text { GSA } \\
\text { Pattern }\end{array}$ & Item & $\begin{array}{l}\text { ASH } \\
\text { Pattern }\end{array}$ & Item & $\begin{array}{l}\text { APC } \\
\text { Pattern }\end{array}$ & Item & $\begin{array}{l}\text { SI } \\
\text { Pattern }\end{array}$ & Factor & $\begin{array}{l}\text { SA } \\
\text { Pattern }\end{array}$ \\
\hline 8 & 0.45 & 1 & 0.94 & 4 & 0.25 & 15 & 0.55 & GSA & 0.99 \\
\hline 10 & 0.88 & 2 & 0.94 & 5 & 0.38 & 16 & 0.78 & APC & 0.95 \\
\hline 18 & 0.91 & 3 & 0.84 & 6 & 0.77 & 17 & 0.86 & ASH & 0.86 \\
\hline 23 & 0.86 & & & 7 & 0.70 & 21 & 0.89 & & \\
\hline 24 & 0.82 & & & 9 & 0.85 & 22 & 0.83 & & \\
\hline
\end{tabular}




\begin{tabular}{|l|l|l|l|l|l|l|l|l|l|}
\hline 28 & 0.88 & & & 11 & 0.80 & & & & \\
\hline 29 & 0.62 & & & 12 & 0.76 & & & & \\
\hline & & & & 13 & 0.55 & & & & \\
\hline & & & & 14 & 0.84 & & & & \\
\hline & & & & 25 & 0.74 & & & & \\
\hline
\end{tabular}

Note. GSA = General Suicide Assessment; ASH = Assessment of Suicide History; APC = Assessment of Personal Characteristics; SI = Suicide Intervention; SA = Second Order Suicide Assessment.

\section{Comparison of Counseling Students and Faculty}

The results of the independent sample t-test on the General Suicide Assessment subscale indicate that on average, faculty scored significantly higher $(\mathrm{M}=30.25, \mathrm{SD}=4.02)$ than counseling graduate students $(\mathrm{M}=22.06, \mathrm{SD}=5.56), \mathrm{t}=\_10.92(170), \mathrm{p}<.01$. The results of the independent sample t-test on the Assessment of Personal Characteristics subscale indicate that on average, faculty scored significantly higher $(M=43.09, \mathrm{SD}=5.81)$ than counseling graduate students $(\mathrm{M}=33.55, \mathrm{SD}=6.67), \mathrm{t}=\_9.91(170), \mathrm{p}<.01$. The results of the independent sample $\mathrm{t}$-test on the Assessment of Suicide History subscale indicate that on average, faculty scored significantly higher $(\mathrm{M}=14.01, \mathrm{SD}=1.68)$ than counseling graduate students $(\mathrm{M}=10.78, \mathrm{SD}=$ $2.75), t=\_9.17(170), \mathrm{p}<.01$. The results of the independent sample t-test on the Suicide Intervention subscale indicate that on average, faculty scored significantly higher $(M=21.27$, $\mathrm{SD}=3.20)$ than counseling graduate students $(\mathrm{M}=16.86, \mathrm{SD}=3.20), \mathrm{t}=-7.63(170), \mathrm{p}<.01$. General Suicide Assessment consists of 7 items, for a maximum score of 35. Assessment of Personal Characteristics has 10 items, for a maximum score of 50. Assessment of Suicide History has 3 items, for a maximum score of 15. Suicide Intervention has 5 items, for a maximum score of 25 . The total possible score on the CSAES is 125 , with higher scores indicating a higher levels of self-efficacy related to suicide assessment and intervention.

\section{Discussion}

The purpose of this study was to develop and test the validity of use of the CSAES in order to measure counselors and counselors in training level of self-efficacy specific to suicide assessment and intervention. Based on the findings, the CSAES scores show both structural aspects of validity and sensitivity to detect differing levels of self-efficacy. We identified and cross-validated a four-factor model representing aspects of suicide assessment and intervention. The second-order factor of Suicide Assessment was also found to adequately represent the data, both theoretically and empirically. In addition, as expected, students scored significantly lower than faculty on all of the CSAES scales.

Typically, in EFA, it is common practice to delete items that are found to cross-load between factors. This is because each factor should uniquely represent an underlying construct. However, because micro-skills specifically related to suicide assessment and intervention are so closely related, these items were not deleted from the factor structure. Lent and colleagues (2003) also 
found that several self-efficacy items measuring counselor micro-skills cross-loaded in the development of the Counselor Activity Self-Efficacy Scales. Further, we determined that removing such items would reduce the adequate representation of differing aspects of suicide assessment and intervention. Therefore, cross-loading items remained in the EFA, but were not modeled as such in the CFA. This allowed the testing of whether items truly belonged in the scale.

Figure 1 contains the final version of the CSAES. Items have been renumbered for the final survey, as during the EFA and CFA 4 items were removed from the scale. Items 1-7 belong to the factor General Suicide Assessment, Items 8-17 belong to Assessment of Personal Characteristics, Items 18-20 belong to Assessment of Suicide History, and Items 21- 25 belong to Suicide Intervention. There are two ways that CSAES can be scored, based on research or training purpose. Each assessment-related scale can be scored individually to get a more detailed understanding about what, if any, differences in self-efficacy exist between differing aspects of suicide assessment.

It would also be reasonable for researchers interested more broadly in suicide assessment to sum the three assessment-related scales (Items 1-20) and sum the intervention scale (Items 21-25). Because each scale has a different number of items, in order to compare levels of self-efficacy, we recommend dividing the mean score for each scale by the number of items. This will allow researchers to study whether counselors or counselors in training have different levels of selfefficacy related to specific aspects of suicide assessment and intervention. For example, in this study, on average students had similar levels of self-efficacy related to General Suicide Assessment $(M=3.15)$, Assessment of Personal Characteristics $(M=3.35)$, and Suicide Intervention ( $\mathrm{M}=3.37)$. Students level of self-efficacy related to Assessment of Suicide History (averaged score 3.60) was the highest. This comparison allows researchers to readily see that students are typically more efficacious in assessment of previous suicidal attempts and family history of suicide than assessment and intervention of current suicidal idealizations. Their scores indicate they are moderately confident in all four areas.

On average, faculty had much higher levels of self-efficacy than students in all four areas with scores indicating their levels are generally confident. Similar to students, the area where faculty feel most efficacious is related to Assessment of Suicide History $(M=4.67)$; whereas faculty have similar levels of self-efficacy related to General Suicide Assessment $(M=4.30)$, Assessment of Personal Characteristics $(M=4.30)$, and Suicide Intervention $(M=4.25)$.

Implications

This study shows support that self-efficacy related to suicide assessment is a four-factor model for counseling practitioners and counseling faculty. We find that counselors' self-efficacy related to suicide assessment is multidimensional, and therefore, how confident they feel in their ability to assess may depend on what aspect/aspects of the assessment are being specifically referenced. 
This could mean that counseling practitioners who experience anxiety while performing suicide assessments or who lack confidence in their suicide assessment skills may not actually have as much difficulty with asking questions related to history, but rather, may lack confidence in their ability to take appropriate action afterward or to ask some of the more personal questions related to current risk factors or warning signs for suicide. In order to build suicide assessment selfefficacy, it may be important for counselor education programs to target the factor or factors that counselors in training feel less comfortable with, by building in opportunities to practice (Bandura, 1986).

There are a number of different factors that can make doing a suicide assessment and intervention on a student difficult for a counselor. Below are listed several warning signs, risks, and potential situations that a counselor may have to face in performing a suicide assessment or intervention. Please read each statement and circle the number that most closely corresponds with your level of confidence, using the following scale:

$\begin{array}{ccccc}1 & 2 & 3 & 4 & 5 \\ \text { Not } & \text { Slightly } & \text { Moderately } & \text { Generally } & \text { Highly } \\ \text { Confident } & \text { Confident } & \text { Confident } & \text { Confident } & \text { Confident }\end{array}$

I. I can effectively inquire if a student has had thoughts of killing oneself.

2. I can effectively assess hopelessness.

3. I can effectively assess whether a student has means to carry out a suicide plan.

4. I can effectively inquire whether a student has a suicide plan.

5. I can effectively counsel a student who has had a history of making suicidal threats, but has had no attempts.

6. I can effectively counsel a student who has previously attempted suicide.

7. I am able to assess a student's level of risk for a suicide attempt.

8. I can help prevent a suicide attempt.

9. I can effectively ask a student about his or her drug or alcohol abuse.

10. I can effectively ask a student about his or her history of sexual abuse.

II. I can effectively ask a student about his or her history of mental illness.

12. I can effectively ask a student questions to assess whether he or she has low self-esteem.

13. I can effectively inquire whether a student has withdrawn from relationships.

14. I can effectively assess a student's acceptance of sexuality.

15. I can effectively talk with a student about his or her hygiene.

16. I can effectively discuss with a student his or her writings about death.

17. I can appropriately inquire whether a student has been a victim of abuse.

18. I can effectively ask a student about his or her previous suicide attempts.

19. I can effectively ask a student about his or her personal history of self-harming behavior.

20. I can effectively ask a student about his or her family history of suicide.

21 . I know the point at which I need to break confidentiality.

22. I am able to appropriately intervene if a student reports suicidal thoughts, but I do not believe him or her.

23. I am able to intervene appropriately if a student denies suicidal thoughts, but I do not believe him or her.

24. I can appropriately take action if I determine a student is moderately at risk for suicide.

25 . I can appropriately intervene if a student is at imminent risk for suicide.

Figure 1. Counselor Suicide Assessment Survey 


\section{Limitations and Future Work}

The data used for this study were collected through three listservs and 11 graduate counseling courses. Participants in the survey may have more interest in suicide assessment than those that chose not to take the survey. In addition, the participant size is relatively low for factor analysis. Simulation studies have indicated that when initial communalities are high, a sample size of 150 can produce a stable factor structure (Thompson, 2004). The CSAES did meet this criteria and was confirmed in the CFA, indicating that the factor structure was stable was for this group. Another limitation is that the diversity of participants is unknown due to ethnicity inadvertently being left-off of the demographic questionnaire. Future work on the CSAES should include examining the factor structure again, with known racial diversity, to further finalize the assessment and better address ethical considerations around multicultural issues and diversity in assessment (ACA, 2014). A multi-group CFA could be used to test the measurement invariance between groups, and help determine whether the CSAES functions the same for differing groups. In addition, applications of item response theory could be used to test item bias. Once evidence has been shown that CSAES functions similarly for diverse groups, researchers should consider whether there are differences in scores between diverse groups.

\section{Declaration of Conflicting Interests}

The author(s) declared no potential conflicts of interest with respect to the research, authorship, and/or publication of this article.

\section{Funding}

The author(s) disclosed receipt of the following financial support for the research, authorship, and/or publication of this article: This research was funded by an award from the Purdue Research Foundation.

\section{References}

American Association of Suicidology. (2013). Warning signs and risk factors. Retrieved from http://www.suicidology.org/ncpys/Warning-Signs-Risk-Factors

American Counseling Association. (2014). Code of ethics. Alexandria, VA: Author.

Bandura, A. (1986). Social foundations of thought and action: A social cognitive theory. Upper Saddle River, NJ: Prentice Hall.

Bandura, A. (2006). Guide for constructing self-efficacy scales. In T. Urdan \& F. Pajares (Eds.), Self-efficacy beliefs of adolescents (pp. 307-337). Charlotte, NC: Information Age Publishing.

Blair, J., Czaja, R. F., \& Blair, E. A. (2014). Designing surveys: A guide to decisions and procedures. Thousand Oaks, CA: Sage. 
Byrne, B. M. (2012). Structural equation modeling with Mplus: Basic concepts, applications, and programming. New York, NY: Routledge Academic.

Center for Disease Control and Prevention. (2012). Suicide: Facts at a glance. Retrieved from http://www.cdc.gov/violenceprevention/pdf/suicidedatasheet-a.pdf

Council for Accreditation of Counseling and Related EducationalPrograms. (2009).

Standards.Retrieved from http://www.cacrep.org/wp-content/uploads/2013/12/2009-

Standards.pdf

Fabrigar, L. R., Wegener, D. T., MacCallum, R. C., \& Strahan, E. J. (1999). Evaluating the use of exploratory factor analysis in psychological research. Psychological Methods, 4, 272-299. doi:10.1037/1082-989X.4.3.272

King, K. A., Price, J. H., Telljohann, S. K., \& Wahl, J. (1999). How confident do high school counselors feel in recognizing students at risk for suicide? American Journal ofHealth Behavior, 23, 457-467. doi:10.5993/AJHB.23.6.5

King, K. A., \& Smith, J. (2000). Project SOAR: A training program to increase school counselors' knowledge and confidence regarding suicide prevention and intervention. Journal of School Health, 70, 402-407. doi:10.1111/j.1746-1561.2000.tb07227.x

Larson, L. M., \& Daniels, J. A. (1998). Review of the counseling self-efficacy literature. Counseling Psychologist, 26, 179-218. doi:10.1177/0011000098262001

Lent, R. W., Hill, C. E., \& Hoffman, M. A. (2003). Development and validation of the Counselor Activity Self-Efficacy Scales. Journal of Counseling Psychology, 50, 97-108. doi:10.1037/00220167.50.1.97

Muthen, L. K., \& Muthen, B. O. (April 2010). Mplus user's guide. (6th ed.). Los Angeles, CA: Authors.

Netemeyer, R. G., Bearden, W. O., \& Sharma, S. (2003). Scaling procedures: Issues and applications. Thousand Oaks, CA: Sage.

Thompson, B. (2004). Exploratory and confirmatory factor analysis: Understanding concepts and applications. Washington, DC: American Psychological Association.

Thompson, B., \& Daniel, L. G. (1996). Factor analytic evidence for the construct validity of scores: A historical overview and some guidelines. Educational and Psychological Measurement, 56, 197-208. doi:10.1177/0013164496056002001

Tinsley, H. E., \& Tinsley, D. J. (1987). Uses of factor analysis in counseling psychology research. Journal of Counseling Psychology, 34, 414. doi: 10.1037/0022-0167.34.4.414 
Wachter Morris, C. A., \& Barrio Minton, C. A. (2012). Crisis in the curriculum?: New counselors' crisis preparation, experiences, and self-efficacy. Counselor Education and Supervision, 51, 256-269. doi:10.1002/j.155 6-6978.2012.00019.x

Worthington, R. L., \& Whittaker, T. A. (2006). Scale development research a content analysis and recommendations for best practices. The Counseling Psychologist, 34, 806-838. doi:

$10.1177 / 0011000006288127$

\section{Author Biographies}

Kerrie Anna Douglas is a visiting assistant professor at Purdue University. She holds a Master's of Science in Education degree in School Counseling and a PhD in Educational Psychology, both from Purdue.

Carrie Wachter Morris is an associate professor in School Counseling at the University of North Carolina at Greensboro. She holds a doctoral degree in Counseling and Counselor Education from the University of North Carolina at Greensboro. Her scholarship interests include pedagogy and practical applications of research in counselor education. 